\title{
EDITORIAL
}

\section{The Army and the Cochrane Collaboration}

Perhaps the greatest change in the practice of medicine which is likely to take place in the next decade is a shift to knowledge-based practice (1). Traditionally doctors base their everyday decisions on a mixture of knowledge based on personal experience, medical school teachings, reading of "expert" articles or talking to colleagues. Such practice is increasingly called into question for two reasons. Firstly, knowledge acquired in this fashion is usually based on partial and sometimes outdated information; secondly as little critical appraisal is usually conducted, doctors have little idea of its limitations.

The NHS solution to this quandary has been the founding in 1991 of its Research and Development (R\&D) programme to which it devotes $1.5 \%$ of its funding (2).

However, setting up a research programme is not enough. In 1988 the House of Lords recognised that the policy-making and research functions had to be closely linked if the former were not to promulgate policy based on guesswork and the latter to be something more than ruminations in an ivory tower (3).

The great Scottish epidemiologist Archie Cochrane spotted these inconsistencies and in 1972 suggested that as society's resources would always be limited it was the duty of doctors to ensure that they were committed equitably to those interventions which in properly designed experiments had been shown to be effective, i.e. achieve their purpose (4). Cochrane stressed the importance of using evidence from Randomised Controlled Trials (RCTs) as these studies were most likely to give us the highest quality of evidence. The Cochrane Collaboration has evolved to put this vision into practice. The Collaboration is an international network of individuals who share a common goal: that of basing decisions on the best available scientific evidence. The Collaboration is based on a network of Collaborative Review Groups (CRGs) whose function is to identify, collect, and sum-up the evidence on the effects of health care across a wide spectrum of problems or activities ranging from pregnancy and childbirth, to musculoskeletal problems and health economics. The output of CRGs are Cochrane Reviews, up-to-date summaries of RCTs which are then entered in the Cochrane Database of Systematic Reviews. A growing number of Cochrane Centres (at present in Oxford, Copenhagen, Baltimore, Milan, Ontario, Australia, The Netherlands and San Francisco), funded by host governments sustain the groups.

The concept of allocation of resources on the basis of who is most likely to benefit forms the basis of casualty triage which military doctors have been practising for two centuries. As the Army shrinks and resources get tighter we are going to be increasingly called to make difficult decisions both on the battlefield and in peacetime practice and justify such decisions in front of a non-sympathetic audience.

There are several reasons why military doctors may want to become part of CRGs. Firstly, reviewing, although hard work, is professionally very satisfying as the reviewer often feels the thrill of stepping where no person has been before. As at present Cochrane reviews do not specifically address problems encountered in military practice in comparable age groups, the research agendum is huge and the scope ample. Secondly such research, once regarded as esoteric or necessary only to pass exams, is increasingly sought by decision-makers (such as the MOD) to guide policy. Cochrane Reviews will carry increasingly more weight and providers in Defence Agencies may be increasingly dependant on the outcome of the reviews. Thirdly, the interface within the Collaboration allows a host of personal contacts to be made and swift professional development to take place.

At present the Army Medical Directorate haso으 commissioned a review on the effects and cost o $\Phi$ interventions to prevent and/or treat musculo-skeleta problems in age groups similar to those in the Forces. Th $\$$ review will be conducted by a military trainee orthopaedie surgeon under the direction of the professor of orthopaedic surgery at Edinburgh University (who is the Editor of the appropriate CRG). The result will guide choices of resource allocation, as the MOD will inves principally in effective and efficient interventions. It is likely that other reviews will be commissioned in the future on topics strictly related to military medicine.

At the same time a volunteer has commenced the handsearching of issues of this Journal back to 1947 with the aim of setting up a register of randomised and quasirandomised controlled trials which will be used as a resource world-wide by anybody interested in the specific areas covered by the retrieved trials.

We military doctors face demanding but exciting times, and must make the most of what is available, for our soldiers and dependents, for British society and for ourselves. The Cochrane Collaboration is a vehicle for expanding our vision and making our practice

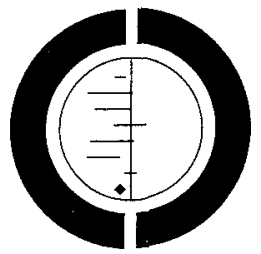

\section{THE COCHRANE COLLABORATION}

Preparing maintaining and disseminating systematic reviews of the effects of health care 
unassailable, in other words, based on the best available evidence.

The Cochrane Collaboration Logo (from the Cochrane Collaboration Handbook) illustrates a systematic review of data from seven RCTs. Each horizontal line represents the results of one trial (the shorter the line, the more certain the result); the diamond represents the combined results. The vertical line illustrates the position around which the horizontal lines would cluster if the two treatments compared in the trials had the same similar effects; if a horizontal line touches the vertical line, it means that particular trial found no clear difference between the treatments. The position of the diamond to the left of the vertical line indicates that the treatments studied are beneficial.

This diagram shows the results of a systematic review of RCTs of a short, inexpensive course of a corticosteroid given to women expected to give birth prematurely. The first of these RCTs was reported in 1972. The diagram summarises the evidence that could have been revealed had the available RCTs been reviewed systematically a decade later: it indicates strongly that corticosteroids reduce the risk of babies dying from the complications of immaturity. By 1991, seven more trials had been reported, and the picture in the logo had become still stronger. This treatment reduces the odds of the babies of these women dying from the complications of immaturity by 30 to 50 per cent.
Because no systematic review of these trials had been ${ }^{c}$. published until 1989 , most obstetricians had not realised that the treatment was so effective. As a result, tens of thousands of premature babies have probably suffered and died unnecessarily (and cost the health services more than was necessary). This is just one of many examples of theo human costs resulting from failure to perform systematic, up-to-date reviews of RCTs of health care.

If any reader is interested in knowing more about the collaboration write to me at: Ministry of Defence, Army Medical Directorate, Keogh Barracks, Ash Vale, Hantsō GU12 5RR.

\section{REFERENCES}

1. SMITH R. Towards a knowledge based health service.c. Br Med J 1994; 309:217-8 (editorial).

2. Peскнам M. Research and Development for the National Health Service. Lancet 1991; 338:367-71?

3. House of Lords Select Committee on Science and Technology. Priorities in medical research. London HM Stationery Office, 1988.

4. Cochrane AL. Effectiveness and Efficiency. Randomo reflections on health services. London Nuffiedd Provincial Hospitals Trust, 1972.

\section{ACADEMIC ACHIEVEMENTS}

\section{FRCA}

MRCGP
Captain GT Bell, RAMC

Major DMS Collins, RAMC

Major AC Francis, RAMC

Major RJ Greaves, RAMC

Major SV Lloyd-Davies, RAMC

Major JAG Marshall, RAMC

Major ATG McCubbin, RAMC

Major GM Moffat, RAMC

Major CD Morris, RAMC

Major AE Murdoch, RAMC

Major CWD Scott, RAMC

Captain RDJ Archer, RAMC

Captain ADW Bone, RAMC

Captain RJ Bramley, RAMC

Captain MD Coombe, RAMC

Captain RJF Ede, RAMC

Captain SK Hall, RAMC 